\title{
artículos
}

\section{Danza distinguida, las piezas de La Ribot}

\author{
Amparo Écija Portilla
}

Investigadora vinculada a la Universidad de Jaén

RESUMEN

El presente trabajo estudia las aportaciones de la coreográfa María Ribot, en la definición de una nueva escritura coreográfica con la cual iba a cuestionar los límites espaciales, temporales y conceptuales de la danza.

PALABRAS CLAVE: Danza/ Vanguardia/ María Ribot.

Distinguished dance. La Ribot's Works

ABSTRACT

This article is about Maria Ribot's work and her vanguard proposals for dance's renovation and its spatial, temporary and conceptual limits.

KEY WORDS: Dance/ Vanguard/ María Ribot.

En el verano de 1993, inspirada por la imagen de una sardina muerta tirada en la calle, la coreógrafa María Ribot (Madrid, 1962) compuso Muriéndose la sirena, su primera Pieza distinguida. Inmóvil, desnuda, tumbada en el suelo, con una sábana de hotel cubriendo parte de su cuerpo y una peluca, su quietud sólo era interrumpida por los últimos espasmos de la sirena antes de morir acompañados por la grabación del sonido de un camión de basura. Esta sería la primera de una serie de 34 piezas con las cuales esta artista, formada en danza clásica y contemporánea, se proponía crear una nueva escritura coreográfica con la cual iba a cuestionar los límites espaciales, temporales y conceptuales de la danza, y que la ha situado como una de las artistas más representativas de la nueva danza europea.

Este movimiento engloba el trabajo de una generación de coreógrafos que había surgido a comienzos de los noventa en diferentes lugares de Europa y que compartían la voluntad de dar un nuevo sentido a la danza. Si bien las propuestas artísticas de todos ellos resultaban muy heterogéneas en forma y contenido, compartían una serie de características comunes que les conferían el carácter de grupo y que definían lo que entonces se empezó a conocer como nueva danza, danza conceptual, danza experimental, danza minimalista, no-danza... sin que llegara a fijarse un nombre concreto. Algunos de estos rasgos eran: el formato de solo, la inmovilidad, el acercamiento al cuerpo, la economía de recursos, el carácter experimental, la

* ÉCIJA PORTILLA, Amparo: "Danza distinguida, las piezas de La Ribot", en Boletín de Arte n 32-33, Departamento de Historia del Arte, Universidad de Málaga, 2011-2012, págs. 233-249. Fecha de recepción: Noviembre de 2010. 
transdisciplina, el deseo de confrontación con el lenguaje y la experimentación con el dispositivo escénico.

Durante los primeros años de su trayectoria María Ribot trabajó en proyectos grandes como directora de la compañía Bocanada Danza (1986-1988), pionera de la danza contemporánea en Madrid que se convirtió en una plataforma de experimentación donde se reunieron bailarines, músicos y artistas de otras disciplinas. El lenguaje que La Ribot empleaba en Bocanada se situaba todavía dentro de la tendencia de la danza-teatro europea de los ochenta, si bien ya comenzaban a aparecer algunas de las constantes estéticas que impregnarán su lenguaje, especialmente en su primera pieza: Carita de ángel (1985). Con la disolución de la compañía, la coreógrafa inicia el recorrido hacia la elaboración de un nuevo lenguaje coreográfico cuyo primer signo importante fue la introducción de un striptease en una pieza de danza para varios intérpretes, 12 toneladas de plumas (1991), que un año más tarde, con el nombre La Ribot, presentará como la pieza independiente Socorro! Gloria! donde va liberándose de las múltiples capas de ropa que cubren su cuerpo, poniendo de manifiesto su deseo de despojar a la danza de todo lo accesorio. De este modo, la coreógrafa escenificaba su opción por una danza de la levedad cuyas únicas herramientas de escritura serían el cuerpo desnudo y los objetos. Con estos elementos y procedimiento de trabajo más cercano a los artistas plásticos emprende el proyecto de las Piezas distinguidas, una serie de solos miniatura donde el cuerpo se sitúa en un espacio de tensión continua entre la danza, las artes plásticas y el arte de acción.

La Ribot se propuso crear 100 piezas, de momento ha creado 34 reunidas en tres series: 13 piezas distinguidas (1993), Más distinguidas (1997) y Still distinguished (2000). Tras la tercera serie, la coreógrafa decide no crear más piezas y el proyecto distinguido evoluciona hacia un trabajo de espacialización de la memoria que ha ocupado otros formatos, espacios y dimensiones: Despliegue (2001), vídeo-instalación que reunía de forma fragmentada las 34 piezas; Anna y las más distinguidas (2002), Más distinguidas interpretada por la bailarina Anna Williams; Panoramix (2003), evento de tres horas de duración que recicla y reubica las 34 piezas en el espacio del museo; La Ribot (2004), libro en 2 volúmenes, el primero de imágenes y el segundo de ensayos sobre su obra; y treintaycuatropiècesdistinguées\&onestriptease (2007), película-documento que transforma el trabajo sobre el cuerpo en un trabajo sobre la mirada.

La Ribot comenzó el proyecto de creación de las piezas imponiéndose una serie de normas distinguidas: duración de entre 30 segundos y 7 minutos, el cuerpo desnudo ("por acercarme al cuerpo y porque se viera ese acercamiento" (La Ribot, 2003: 218), partir del silencio y la distinción (la única norma que no tiene explicación). Estas normas se mantienen, se exploran y se cuestionan a lo largo de las tres series hasta que la última pieza, $\mathrm{Pa}$ amb tomàquet (n. 34), rompe con todas ellas al tratarse 
de un trabajo en vídeo. El título es un homenaje al músico Erik Satie (1866-1925) y a su pieza Trois valses distingués du précieux dégôute y en el cual también juega con la ambigüedad que plantea la palabra distinguido: una postura snob, distante y distinguida, un deseo de distinguirse y trabajar la danza de forma diferente, y la idea de fragmentación en oposición al concepto de unidad de una pieza de danza.

A lo largo de las tres series hay una evolución muy clara, desde lo teatral hacia lo puramente visual desde el punto de vista del tratamiento del cuerpo, de su situación en el espacio y de la relación que se establece con el espectador.

"La primera serie trabaja lo teatral. La segunda es más plástica en el sentido de que el cuerpo es trabajado más directamente y se convierte en el lienzo en el que yo voy pegando, pintando o colgando cosas. Su visión tiene que ser totalmente frontal, si no, no funciona. Still distinguished es como si hubiera puesto ese cuerpo aplastado contra el suelo, es decir que se expande por la superficie y ya no se tiene que ver frontal y el espacio comienza a ser muy importante. (...) En la primera estoy dentro de un cubo que es el teatro; en la segunda juego en dos planos, que serían mi cuerpo y la visión; y la tercera serie es una cosa totalmente extendida en la superficie." (La Ribot, 2003: 219).

\section{PIEZAS DISTINGUIDAS (1993).}

"Son pensamientos, imágenes, ideas, que llamo distinguidas y que defiendo como esenciáticas." (La Ribot, 1994).

La Ribot consagra la primera serie de piezas al cuerpo y a la teatralidad, y a través de ellas compone un nuevo lenguaje coreográfico. La opción por la desnudez pone su trabajo en relación con otros coreógrafos conceptuales como Jérôme Bel, Xavier Le Roy o Gilles Jobin, para quienes el desnudo funciona como un medio de objetivización ajeno a cualquier intención expresiva o erótica. La desnudez en La Ribot responde a la búsqueda de un acercamiento al cuerpo y, como ya propusieran los coreógrafos del Judson Dance Group Yvonne Rainer y Steve Paxton en la pieza Word Words (1965), a una mayor neutralidad.

"En primer lugar si yo empiezo a negar el movimiento lo que me da más peso como bailarina es el cuerpo, el cuerpo como medio, y si quiero negarle algunas cosas tengo que desnudarlo, tengo que neutralizar la base sobre la que trabajar. Por ello me parecía que con el desnudo no tengo ninguna connotación, no hay colores, es un lienzo neutro. El cuerpo también es muy político, tiene muchos significados, da mucho más juego un cuerpo desnudo que vestido. El cuerpo de una mujer desnuda habla y significa muchísimo." (La Ribot en Bordonaba, 2001: 28). 


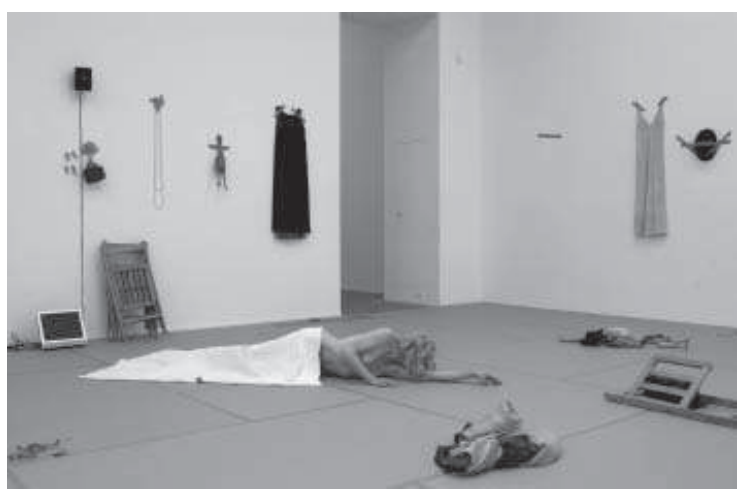

1. Muriéndose la sirena en Panoramix, 2003. Foto: Manuel Vason.

La Ribot reinventa la danza desde la potencialidad de significados del cuerpo desnudo, desde su neutralidad, vulnerabilidad y nobleza; la desnudez está alejada de cualquier sentido erótico. La desnudez potencia la danza de la inmovilidad, la de los movimientos incontrolados del cuerpo, la del temblor de la piel o el sonido de la respiración como sucede desde la primera pieza, Muriéndose la sirena (n.1).

En la segunda pieza, La Ribot corre de perfil de un lado a otro del escenario sujetando frontalmente un trozo de cartón encontrado en un contenedor que cubre su pecho y sus nalgas, acompañada de una canción que escuchaba de niña, Fatelo con $m e$ (n. 2) (Anna Oxa) que da nombre a la pieza. Esta relación con los objetos acerca las Piezas distinguidas a los ready made de Duchamp: "ese objeto de uso común al que una mínima intervención del artista -firma, fecha, presentación a una exposicióny sobre todo una descontextualización y contextualización convierten en obra de arte." (Santos, 1993: 66). En el caso de La Ribot, el objeto encontrado (silla, sábana de hotel, cartón) y el objeto privado (canción, peluca, recuerdo infantil) se adhieren al cuerpo como herramientas de escritura e irán reapareciendo a lo largo del proyecto, desafiando en su perpetuación lo efímero de la danza. Todos los objetos se sitúan a un mismo nivel con los textos, las canciones, los títulos, las acciones y los espacios, en torno al objeto centralizador, el cuerpo desnudo, y con la danza como lenguaje.

El cuerpo de La Ribot nos recuerda constantemente que ha sido formado en el lenguaje de la danza clásica, su fisonomía encarna el cuerpo esbelto, elástico y delgado de bailarina; sin embargo ahora la bailarina, cuyo papel había sido el de obedecer las indicaciones de los maestros, se dispone a desmantelar ese sistema para crear uno propio ${ }^{1}$. La primera serie plantea varias cuestiones en oposición directa

1 "El eterno retorno del ballet en las piezas distinguidas es indisociable de la opción por la levedad, y es precisamente la lucha contra la gravedad, que había justificado toda la disciplina dancística de los bailarines clásicos, lo que fascina y al mismo tiempo divierte a La Ribot. La impotencia ante esta fuerza, que provoca el llanto en Hacia dónde volver los ojos, da lugar a la ironía en 19 equilibrios y un largo, y provoca la memoria de una disciplina cruel en Chair 2000." (Sánchez, 2004: 43). 
con principios dominantes en las coreografías convencionales: la fragmentación, en oposición a la idea de unidad, enfatizada por la duración mínima de las piezas de esta serie, algunas de las cuales no llegan a un minuto (Sin título I (n.3), Cosmopolita (n.7)); la quietud (Muriéndose la sirena) o una nueva concepción del movimiento desvinculado de la idea de flujo que se asocia habitualmente a la danza y que adopta otras formas como los estertores de la sirena, el llanto (Hacia dónde volver los ojos (n. 10)) o el juego con los objetos (Capricho mío (n. 8)). Existen, además, tiempos marcados por acciones ajenas a lo coreográfico, como la duración de un pitillo ( $\mathrm{Ya}$ me gustaría a mí ser pez! (n. 6)), una canción de la infancia (Fatelo con me) o una caída. La caída, un tabú para la bailarina clásica, será una constante en el lenguaje de la coreógrafa, y varias piezas de esta serie ya giran en torno a ella, como la n. 6 - La vaca sueca (n. 9), cuya coreografía consiste en una caída lenta marcada por la duración de una canción tradicional húngara y en la que La Ribot adopta posturas de ballet al tiempo que cubre y descubre su rostro con un bombín. Por otro lado, también hay piezas de esta serie que transcurren íntegramente en el lugar donde antes la bailarina sólo podía morir, el suelo.

La Ribot plantea una nueva forma de trabajar la danza cercana a la del pintor o el escultor, y construye unos solos en miniatura donde el cuerpo se enlaza con los objetos y se establece un diálogo entre la danza, las artes plásticas y el dispositivo escénico. Sin embargo, 13 piezas distinguidas continúa trabajando lo teatral y se mantiene dentro de la caja negra: la iluminación juega un papel muy importante y los espacios de la intérprete y del público están claramente definidos y diferenciados. A pesar de ello, el proceso de reducción de escala, el acercamiento radical al cuerpo provocado por la desnudez, la escala de los objetos, el formato corto y la fragmentación plantean una nueva relación de ligereza y vulnerabilidad con el espectador, habituado hasta entonces a los montajes de las compañías de danza de los ochenta; habiendo incluso piezas donde este acercamiento ocurre de forma explícita y la bailarina recurre al juego ("¡Un, dos, tres al escondite inglés!") para romper la barrera que les separa como sucede en Sin título $I$.

En cualquier caso, la teatralidad mayor de esta serie no sólo deviene del dispositivo sino también de una mayor intencionalidad en el contenido de las piezas. El tema de la violencia de género, que recorre todo el proyecto, aparece ya en piezas como De la vida violenta (n. 4), Hacia dónde volver los ojos o Eufemia (n. 5). En De la vida violenta La Ribot aparece ataviada con un jersey muy amplio y lleva a cabo una coreografía de movimientos mínimos impulsada por algo que sólo ella puede oír, algo que la penetra y la conmueve hasta que se oye un disparo y cae fulminada al suelo. Hacia dónde volver los ojos está inspirada en una imagen de la guerra de Bosnia que había impresionado a la coreógrafa y mostraba a una mujer subida a una silla con el cuerpo doblado hacia delante; el pie de foto explicaba que la mujer había sido abandonada en un hospital psiquiátrico y llevaba días así, llorando y cantando. 
La Ribot crea una pieza en torno al sufrimiento y en la misma postura que la mujer de la foto registra con un micrófono los gemidos del cuerpo que llora. En Eufemia La Ribot lleva un vestido blanco que se cubre de una mancha roja; pronto descubre que la mancha procede de un mecanismo oculto en su pecho que ella misma está presionando y cuyo contenido acabará tiñendo todo su cuerpo: se desangra a sí misma y no puede hacer nada para evitarlo. Se trata de la primera imagen de la mujer sangrante, abierta a muchas interpretaciones y que tendrá una segunda versión en la pieza de la tercera serie Another Bloody Mary (2000).

Otro tema central del proyecto es el humor ${ }^{2}$, muy presente en algunas piezas de esta serie como Cosmopolita (n. 7) o Capricho mío (n. 8). En la primera, ataviada con un llamativo bañador de color verde y un gran turbante rojo en la cabeza, La Ribot realiza una coreografía basada en un juego semántico-asociativo que recorre su cuerpo convertido en un mapamundi. En la segunda, se transforma en una bailarinapez-máquina que cae lentamente el tiempo que dura el cigarro que fuma hasta quedar tendida en el suelo. $Y$ en Capricho mío enrollada en una toalla azul de ducha toma divertidas medidas de su cuerpo con una cinta métrica.

Por lo tanto, el homenaje a Erik Satie en el título del proyecto no es casual, ya que el trabajo de La Ribot entronca con la corriente que se inició a principios del siglo XX con Dadá y que ha utilizando el humor como herramienta "relativizadora (...) que disuelve los límites, que anula las jerarquías sin que por ello el artista pierda su distinción" (Sánchez, 2004: 39). El humor, unido al proceso de reducción de escala y al acercamiento a la forma de trabajar de los artistas plásticos, hace que surja la figura del propietario distinguido. La Ribot, al igual que habían hecho otros artistas como Piero Manzoni (Living Sculpture, 1961) e Yves Klein (Immaterial Pictorical Sensivity Zone $_{5}$, enero 1962), convierte su cuerpo en una obra plástica en venta planteando una nueva forma singular y distinguida de mecenazgo que establece un juego conceptual sobre lo efímero de la danza y una visión irónica sobre el mercado del arte.

13 Piezas Distinguidas tuvo una excelente acogida por parte de la crítica y el público y se presentó en numerosos festivales contribuyendo al temprano reconocimiento de La Ribot en los escenarios alternativos internacionales, lo que motivó a la coreógrafa fijar su residencia en Londres donde llevó a cabo la creación de la segunda serie de piezas, Más Distinguidas.

2 "El proyecto de las piezas distinguidas es incomprensible sin atender a la componente humorística que lo anima. (...) Si podemos hablar de humor a propósito de las piezas distinguidas es porque están pensadas y construidas desde una actitud vital y una actitud creativa que rehúye lo recto, lo pesado, lo fijo y lo aburrido y prefiere en cambio lo lúdico, lo ligero, lo fluido y lo irónico." (Sánchez, 2004: 39). 
MÁs distinguidas (1997)

"En Más Distinguidas el cuerpo es cada vez más un lienzo donde se pegan collages, ideas, vestidos, objetos, sonidos, obsesiones. El color es la carne, la pesadilla los objetos, el espacio aún está lleno." (La Ribot, 1997: 10).

Las trece piezas que constituyen Más Distinguidas continúan estando concebidas para el dispositivo de la caja negra, si bien la sucesión de unas a otras resulta más orgánica que en la serie anterior y el trabajo evoluciona hacia una mayor plasticidad donde el cuerpo se convierte en un lienzo que se pinta o sobre el cual la artista pega o cuelga los objetos.

Un año después de su estreno en la primera edición del festival Desviaciones (1997, Madrid), La Ribot presentó la versión blanca de esta misma serie, con la que da un paso muy importante en la desestabilización de los códigos escénicos y en el acercamiento de la danza al espacio de las artes visuales. Esta alteración del dispositivo elimina los efectos lumínicos, el factor sorpresa y los trucos de la caja negra, mostrando en su totalidad la instalación y desmontaje de cada pieza así como la transición de una pieza a otra, y a pesar de que las piezas son idénticas en ambas versiones, la blancura les otorga una nueva plasticidad.

El espectáculo arranca con Narcisa (n. 16): La Ribot espera desnuda la entrada del público sentada en el suelo. "Cuando se levanta", señala Irene Filiberti, "se adquiere plena conciencia de la envergadura de su presencia, el cuerpo delgado como una línea, la piel blanca y lisa, los cabellos y el vello público teñidos de rojo intenso." (Filiberti, 2006) ${ }^{3}$. A continuación, coge una cámara polaroid, se coloca de pie de perfil, saca una foto de su pecho izquierdo y la pega encima, hace lo mismo con el derecho y con el pubis. Camina de frente y se queda quieta, mirando al público, con los brazos levantados sujetando la cámara en una mano. Permanece inmóvil en esa postura el tiempo que las fotos tardan en revelarse y le permiten recuperar sus pechos y su pubis convertidos en imagen.

En Más distinguidas el cuerpo también se convierte en la superficie para la pintura como sucede en la pieza N. 26 (n. 26) donde al ritmo de un fragmento de Belmonte 4 (Carles Santos, 1988) la artista cubre su piel de trazos azules. Al convertir su cuerpo en un lienzo, La Ribot escenifica su deseo de fusionar la danza y las artes visuales y para ello emplea además otras estrategias, como la de convertirse en La Venus del espejo de Velázquez en la pieza Sin título IV (n. 17) o plantear una pieza como Oh! Compositione! (n. 22) $)^{5}$ sobre la propia acción de componer. En Sin título IV,

3 Texto de Irene Filiberti en www.laribot.com

4 El músico catalán había compuesto esta obra para Belmonte (1988) de los coreógrafos Cesc Gelabert y Lydia Azzopardi.

5 "El trabajo de las piezas consiste en muchas cosas comprimidas en el espacio y en el tiempo. Oh! 
aparece tumbada de espaldas al público y hace girar a lo largo del cuerpo un espejo circular que va mostrando, en movimiento y de forma fragmentada, la parte frontal de su cuerpo. En el espejo va emergiendo la imagen de sus piernas, de su pubis, de su vientre, de su pecho y de su rostro. Es interesante observar cómo se encuentran la imagen y el movimiento en estas tres piezas. El interés de Narcisa no radica en las imágenes sino en el movimiento del revelado de la imagen; en Sin título IV el movimiento del espejo muestra fragmentos fugaces de un cuerpo que se resiste a ser atrapado por la mirada del espectador, y en Oh!Compositione! la acción del cuerpo construye y a continuación destruye la imagen compuesta. El movimiento o su negación son una constante en las piezas distinguidas y en esta serie encontramos piezas más bailadas (N. 26, Missunderstanding o Numeranda) junto a otras más estáticas como Narcisa o Sin título III (n. 23), una pieza de 20 segundos más cercana a los solos-miniatura de la primera serie donde La Ribot sostiene durante unos segundos un pollo de goma y que muestra cómo "una pieza distinguida puede ser un poema móvil, un solitario corto o cortísimo de cualquier pensamiento. Un tableux vivant que se vende. Una coreografía para la mente. Una imagen para tender a secar." (La Ribot, 1997: 10).

La quietud de estas piezas contrasta con otras en las que La Ribot baila en un sentido más convencional de la palabra y en ellas el cuerpo, los objetos, la música y el movimiento construyen diferentes significados. En Numeranda (n. 15), la artista realiza una coreografía marcada por el ritmo de un metrónomo y que se apoya en la repetición y acumulación de secuencias de movimiento por medio de las cuales numera los diez aparatos domésticos cuyos sonidos forman parte de la pieza (un reloj, un teléfono, un microondas, una aspiradora, un lavaplatos, una cafetera, una alarma, etc.); mientras un técnico sujeta dos bandas negras que censuran, como había hecho el cartón en Fatelo con me, su pecho y su pubis, y el cuerpo en movimiento desafía la barrera visual del objeto antepuesto.

A su vez, varias piezas de esta serie se apoyan en la revisión de los elementos básicos de la danza, como 19 equilibrios y un largo (n. 19), Poema Infinito (n. 21) y de forma muy especial Missunderstanding (n. 24), donde La Ribot sintetiza su preocupación en torno a la danza y sus códigos por medio de una coreografía basada en el sistema que utilizan los coreógrafos clásicos para mostrar las diferentes posturas del cuerpo. A medida que avanza la pieza, La Ribot va marcando los pasos de una coreografía imaginaria imposible y se produce un desdoblamiento ya que aparecen dos cuerpos: uno que marca los pasos y se mueve espontáneamente y otro que baila en la imaginación. Este tema se desarrollará plenamente en un trabajo largo posterior, El Gran Game (1999), donde la coreógrafa se apoya en el silencio, el azar y el juego, con el objetivo de investigar sobre la relación entre el lenguaje de signos y los códigos de la danza.

Compositione! es buen ejemplo porque hay muchos elementos que se repiten en muchas piezas: la silla, el cuerpo desnudo, el agua... y luego está ese componente de composición, primero la silla, el vestido, el vaso de agua y al final el clímax." (La Ribot en Luc, 2004). 
El humor impregna también esta serie y permite llevar a cabo un proceso de extrañamiento y disociación entre artista e intérprete que le conduce a comparar su cuerpo al de un pollo desplumado (Sin título III) o a arrastrar el cuerpo hasta la muerte, como en Manual de Uso (n. 20), una pieza tragicómica en la que el cuerpo se convierte en un aparato cuyas instrucciones de uso le conducen a la asfixia, o en N. 14 (n. 14) de carácter más violento. En esta última La Ribot se cuelga al cuello un cartel de cartón donde pone "Se Vende", se encaja una silla de madera a la altura de la cintura y levanta un brazo en postura de ballet. Baja lentamente el brazo y de puntillas, mirando fijamente al público va caminando hacia atrás, se detiene y gira lentamente sobre sí misma hasta quedar de perfil y retroceder hasta el fondo

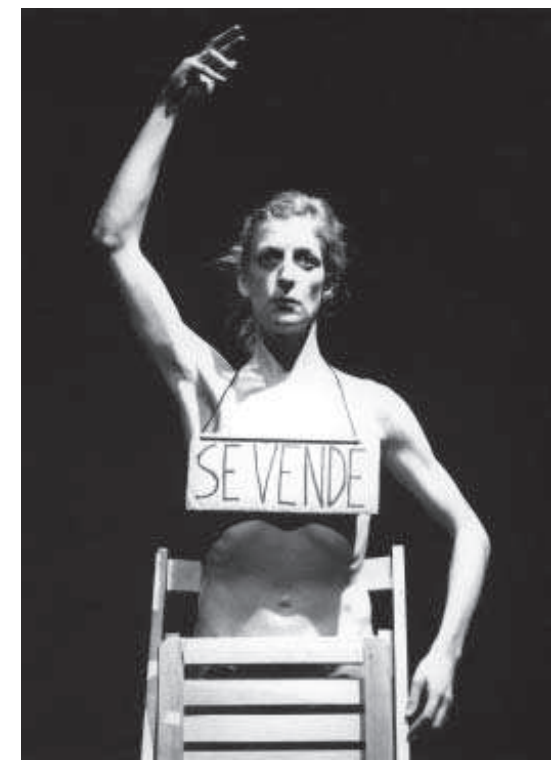

2. N. 14, 1997. Foto: Pau Ros. de la sala donde dobla la silla contra su vientre de forma más violenta al tiempo que cae apoyada contra la pared hasta parar bruscamente y quedar tumbada y paralizada en el suelo ${ }^{6}$. Su fuerza plástica y performativa han convertido a esta pieza en uno de los iconos del proyecto.

Objetos tan significativos como la silla o el cartón se adhieren al cuerpo para construir una pieza que recupera un tema que ya había aparecido en piezas de la serie anterior como Eufemia o Hacia dónde volver los ojos: la violencia sobre la mujer. La silla actuará de nuevo como objeto hostigador en una pieza posterior, Chair 2000 (2000), que dejará inmovilizado el cuerpo de la bailarina. En la pieza Angelita (n. 18) habla de ese cuerpo: ataviada con unas enormes alas de goma espuma de color crudo que agita con un movimiento incesante de jogging, enumera una serie de infinitivos que indican acciones del cuerpo y termina planteando una pregunta al espectador: " ¿de qué cuerpo hablo?". Del cuerpo de la bailarina que, tan acostumbrado a la sumisión y al silencio, había olvidado todo lo que era capaz de hacer. Con esta nueva danza la bailarina recupera la voz y el silencio, el movimiento y la quietud, su memoria y su risa, y es entonces capaz de crear una coreografía sin moverse de una silla, como sucede en Divana (n. 25) donde desde su inmovilidad derriba la barrera que le separa del

6 "La disociación de artista e intérprete resultaba cada vez más clara en este ejercicio en que una ordenaba a la otra que activara el mecanismo de su tortura. Y sumisamente, la intérprete ponía en movimiento una silla que progresivamente la iba reduciendo hasta el fondo del escenario, hasta el suelo, en una especie de prolongada y brutal violación hasta la muerte." (Sánchez, 2006: 328). 


\begin{tabular}{|c|c|}
\hline 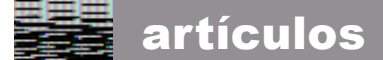 & Amparo Écija Portilla \\
\hline
\end{tabular}

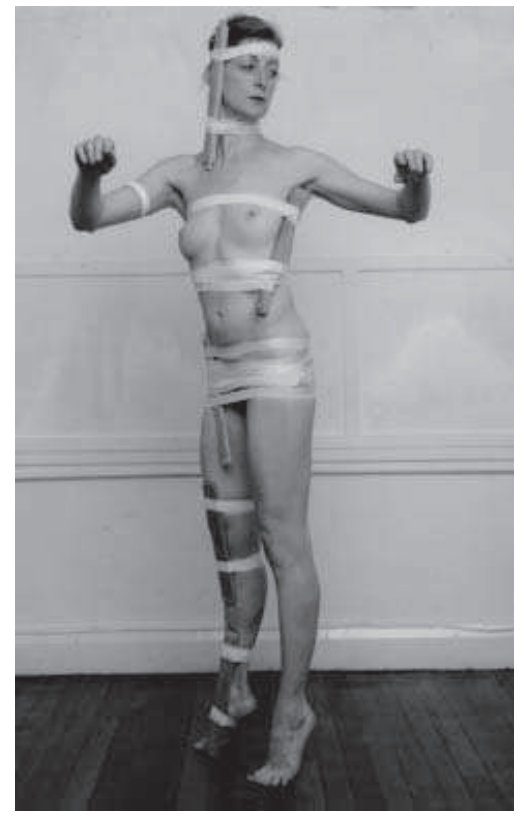

3. Chair 2000, 2000. Foto: Manuel Vason. público transmitiéndole la responsabilidad de la acción durante cuatro minutos. Esta desestabilización de los códigos se enfatiza con la transformación de la caja negra en espacio blanco en la segunda versión de Más distinguidas; la presencia del espectador se vuelve más enfática y las piezas adquieren una nueva calidad plástica y preformativa que culmina en la tercera serie, Still Distinguished, que se sitúa el cuerpo, los objetos y el público en un mismo espacio sin jerarquías, emplazando la danza en el espacio-tiempo expositivo de las artes visuales.

\section{Still distinguished (2000).}

"El punto de partida de Still distinguished es trabajar con lo que significa still: por un lado el estatismo, lo calmado y por otro la continuidad del aún, siendo, todavía, del tiempo que sigue pasando." (La Ribot, 2002: 219, cursivas añadidas).

Con Still distinguished el trabajo se sitúa más cerca de la instalación y del arte de acción: no hay personajes, ni montaje escenográfico, sólo existe lo que vemos y lo que ocurre a tiempo real. El cuerpo de La Ribot no quiere representar nada, sólo ser un cuerpo que en vivo instala y desinstala una serie de piezas y da un tiempo al espectador para que establezca una relación con ellas. La luz blanca es un factor fundamental para hacer posible la idea de presentación, ya que elimina el factor teatral y permite al espectador presenciar el proceso de forma íntegra. Cuando el público entra en el espacio encuentra una serie de objetos esparcidos por la sala a modo de una instalación: una caja roja, la parte de una silla, una peluca rubia, una radio, una cuerda, tablillas.... La Ribot entra en el espacio, enciende los monitores distribuidos por la sala que muestran grabaciones diferentes de una misma acción y vuelve a marcharse. De este modo, la coreógrafa da un tiempo al espectador para que ocupe el espacio y comience a moverse y a situarse al mismo nivel que las herramientas de escritura que observa.

Al tratarse de una pieza filmada, $P a$ amb tomàquet (n. 34) rompe todas las normas del proyecto, salvo la distinción. La cámara se convierte en la extensión de 
un cuerpo en movimiento que se convierte en objeto por medio de una acción coreográfica que consiste en untar ajo, tomate y aceite sobre la piel, y donde la coordinación inconsciente entre música y movimiento revela una vez más la memoria de un cuerpo de bailarina.

"Por mi formación de bailarina intento ir a música, intento cortar el tomate y se me escapa. Se trata de encontrar una explicación diferente a la danza. Mi trabajo es un trabajo para la danza. Más que si es o no es, yo estoy para. $Y$ en el vídeo se ven muchos detalles que cantan a bailarina, a bailarina de un-dos-tres, un-dos-tres... con el ajo de repente estoy siguiendo el ritmo y no lo hacía de manera consciente (...) me gusta mantener esa cosa que me hace ir a ritmo“. (La Ribot, 2003: 224).

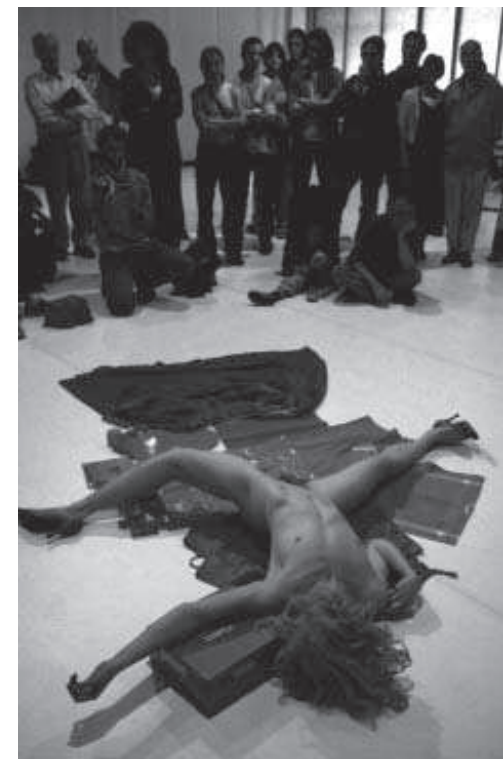

4. Another Bloody Mary, 2000. Foto: Mario del Curto

La transformación de sujeto en objeto recorre toda la serie y se muestra de forma significativa en la pieza que sigue al vídeo: Candida lluminaris (n. 30). En ella La Ribot se entrega a la tarea de alinear una serie de objetos de menor a mayor tamaño dentro del cono de luz que proyecta la pequeña linterna de bolsillo que coloca en el suelo: un cochecito, una muñequita, una horquilla, un miniventilador, un trozo de cartón, un fragmento de silla, una cinta métrica... y al final de la línea sitúa el cuerpo desnudo, tumbado boca arriba que permanece inmóvil durante algo más de 2 minutos, respirando y haciendo un ruido bronco, convertido en un objeto más: "un cuerpo inmovilizante, sonoro, que danza horizontalmente su activa inmovilidad." (Lepecki, 2006: 148).

Si en otras ocasiones los objetos tienen un valor semántico (como los objetos rojos que forman el charco de sangre de Another Bloody Mary), o se adhieren al cuerpo para construir una imagen (como la mujer-bailarina aprisionada por las tablillas de la silla en Chair 2000), en Candida lluminaris son meramente objetos y el cuerpo se convierte en el objeto "clave de la diseminación objetual precedente" (Castro Flórez, 2002: 8). Estos objetos están cargados del recuerdo de las piezas anteriores y a través de ellos La Ribot "lleva a cabo un ejercicio de espacialización de la memoria" (Sánchez, 2004: 46): el miniventilador de Divana, la media de Socorro!Gloria!, la cinta 
métrica de Capricho mío, la radio de Ya me gustaría a mí ser pez, el cartón, la silla... y finalmente el cuerpo ${ }^{7}$.

En Still Distinguished, las piezas se suceden unas a otras expandidas en la superficie en contraposición al concepto vertical y acumulativo de las dos primeras series. Al finalizar Candida Iluminaris, La Ribot regresa a la fila de objetos para apagar el ventilador y la radio, se pone el zapato rosa y, seguida por el público, empieza la construcción de la próxima pieza: Outsized Baggage (n. 28). Coge una cuerda del suelo y la ata alrededor del cuerpo desnudo como si fuera un paquete: primero varias vueltas a la cabeza (de la barbilla a la coronilla); varias vueltas al cuello, luego el torso, las caderas; camina con dificultad para coger otro objeto, se ata las rodillas, las piernas, los tobillos, hasta quedar perfectamente atada e inmovilizada; para terminar se coloca una cinta de identificación de equipaje del aeropuerto de Heathrow como las bandas en los concursos de belleza y se queda de pie, inmóvil, en puntas (un pie elevado por el tacón) durante algo más de 2 minutos: “... el cuerpo desnudo permanece inmóvil, soportando, con un raro hieratismo, la lógica de los no lugares, esa conversión del mundo en un inmenso mostrador de tránsito." (Castro-Flórez, 2002: 7).

La inmovilidad del cuerpo atrapado de Outsized Baggage se repite en Chair 2000 (n. 29) ${ }^{8}$, donde deconstruye la imagen idealizada de la bailarina en puntas y también denuncia la violencia silenciosa que ha oprimido durante siglos a la mujer. En Chair 2000 reaparece la silla hostigadora de $N$. 14 pero en esta ocasión fragmentada en tablillas, con el objetivo de acentuar el carácter visual de esta serie, que la bailarina pega al cuerpo con esparadrapo bloqueando las articulaciones; una vez ha quedado inmovilizada realiza, en puntas y con los brazos elevados, un giro de $180^{\circ}$ durante dos minutos.

Estas dos piezas suceden en el plano vertical y enfatizan, como ocurre en el ballet, la perpendicularidad del torso, en contraste con el resto de piezas de la serie donde se pondera la horizontalidad del soporte de esta danza de la inmovilidad, como sucede en Another Bloody Mary (n. 27). En esta pieza La Ribot compone un tapiz de color rojo con sus objetos fetiche sobre el cual caerá un cuerpo cuya identidad sexual

7 "Cuando en Candida Illuminaris La Ribot se desprende de todos sus objetos y toda su ropa, parece desprenderse con ello de su memoria, de su identidad, y convertirse momentáneamente en objeto, en instrumento ejecutante de una serie de acciones ideadas por un sujeto que ha quedado dispuesto sobre el suelo. (...) Es como si La Ribot tratara de recuperar la memoria de sus propias acciones, efímeras, desconocidas por tanto para muchos espectadores, llenar de identidad el espacio. O como si se tratara de desvelar los signos que han compuesto y componen su código básico de escritura: objetos cotidianos, anodinos o caprichosos." (Sánchez, 2003b: 14-18).

8 “(...) La pieza Chair 2000 concentra significados en un punto álgido, el único en toda la actuación, un "relevé" entablillado de filete de mujer y silla de palo. El significado de chair en francés es carne y en inglés es silla. De las dos superficies planteadas en Still distinguished, la horizontal del suelo donde nos encontramos todos y la superficie de mi cuerpo, es decir, la piel, es quizás ésta la más fina y sensible. Es con ella que me separo y me pego a los otros, al espectador, y es sobre esa fina frontera entre lo exterior y lo interior que me unto el ajo, el aceite y el tomate, que me ato como un paquete y que me pego la silla. Si esta piel es además enorme, es también porque tiene volumen, es decir interior, que relleno de agua primero y después de aire, ambas cosas transparentes. (...) La Ribot. Londres oct. 01." (La Ribot, 2002: 17). 
ha sido anulada por las pelucas que cubren la cara y el sexo. Another Bloody Mary expone de forma muy clara cómo La Ribot trabaja con el still: en el sentido del durante, con la acción de colocar los objetos y la caída radicalmente lenta sobre ellos, y en el sentido de lo estático, el cuerpo destrozado que yace inmóvil sobre una mancha roja y que produce una imagen muy violenta y cargada de ambigüedad expuesta a la mirada y a la presencia del espectador.

La inmovilidad y el silencio potencian la idea de presentación en oposición al concepto de representación escénica que se pone especialmente de manifiesto en las dos últimas piezas en vivo de la serie: Zurrutada (n. 32) y S-liquide (n. 33), donde "comienza a ser más un cuerpo acentuado por lo que sucede en el presente, por eso se acerca más a la acción" (La Ribot, 2003: 225):

"No hay más representación, sólo presentación. / No hay más magia, sólo realidad. / No hay más sorpresas, sólo percepciones variables. / No hay más declaraciones, sólo ambigüedad. / No hay más estabilidad, sólo desequilibrio. / No hay más teatralidad, sólo plasticidad." La Ribot. Londres, Septiembre de 1999." (La Ribot, 2002: 30).

En Zurrutada la artista coge una botella de cristal de un litro y medio de agua y comienza a beber acompañada de la pieza 55921, del grupo suizo de música experimental Velma, que rige la duración de la acción. Va cayendo muy lentamente sin dejar de beber hasta quedar tendida inmóvil en el suelo durante unos minutos. En S-liquide se recupera la imagen de la sirena inmóvil con la que se había iniciado el proyecto (Muriéndose la sirena, 1993) y se despliega de nuevo en todo su esplendor la danza de la quietud, el silencio y la desnudez se despliegan. La segunda sirena yace desnuda en el suelo envuelta en el material utilizado para cubrir cadáveres, tiene un micrófono situado debajo de su estómago que desvelará cualquier movimiento, por mínimo que sea, a través del sonido del papel metalizado. La pieza tiene una duración de siete minutos, durante los cuales deberá contener al máximo la respiración para no desvelar los leves movimientos inevitables en su inmovilidad que revelan que "aunque ese cuerpo desnudo funciona a veces como una imagen, esa imagen tiembla siempre sutilmente, revela siempre su naturaleza fisiológica por medio de pequeñas tensiones, sus latidos, dudas, desequilibrios, estremecimientos, contracciones, dilataciones... los inagotables elementos cinéticos de las pequeñas danzas y actos inmóviles de La Ribot." (Lepecki, 2006: 148-149). La inmovilidad sitúa el trabajo de La Ribot en relación al de otros coreógrafos europeos como Jérôme Bel, Xavier Le Roy o Juan Domínguez, quienes también han decidido romper con una idea de danza unida a flujo de movimiento, cuestionando, desde la inmovilidad, sus límites conceptuales, espaciales y temporales por medio de un diálogo desde el cuerpo con otros procedimientos de escritura y estableciendo una nueva relación con el público.

En Still Distinguished La Ribot sitúa al público en el lugar de la acción y la 
inmovilidad de la artista provoca que el espectador componga su propia coreografía al tener que decidir qué relación (mirada, cercanía) desea establecer con cada pieza. Este hecho supone la transgresión definitiva de los códigos escénicos y completa la secuencia que la coreógrafa había iniciado en una pieza temprana de su trayectoria, 12 toneladas de plumas (1991), con la figura del público inventado, y que había continuado en las primeras series mediante piezas que desafiaban la barrera que la separaba del público -jugando al escondite inglés en Sin título I o compartiendo los minutos de silencio, reflexión y meditación en Divana-, o la transformación en caja blanca de la segunda versión de Más Distinguidas (1998) que dejaba al descubierto todos los rostros. Still distinguished supone la culminación de este proceso y es el origen de un trabajo posterior: 40 espontáneos (2004), que completa la secuencia ya que está representado por 40 intérpretes sin experiencia escénica elegidos en cada lugar donde se presenta la pieza.

Tras Still distinguished, La Ribot deja de componer piezas distinguidas, pero el proyecto continúa ocupando otros espacios, formatos y dimensiones que continúan el nuevo planteamiento creativo anunciado en la tercera serie de piezas tras la desaparición del cuerpo: la escritura de la memoria. En 2001 y 2003 realiza en Londres dos obras que reúnen las 34 piezas distinguidas: la vídeo-instalación Despliegue y el espectáculo en vivo Panoramix. Ambos constituyen una revisión, un reciclaje y un viaje por el proyecto de las piezas distinguidas. Despliegue supone un segundo striptease en el cual la coreógrafa se desprende de los objetos que habían compuesto las piezas distinguidas y que escriben la memoria fragmentada del proyecto: los objetos cotidianos y caprichosos (las pelucas, los vestidos, el pollo de goma, el espejo, la silla y el cartón en sus diferentes versiones, muñequitos, zapatos, etc.), las acciones (la inmovilidad, las caídas, las reverencias, el morir en el suelo, vestirse, desvestirse, pegarse objetos, desprenderse de objetos, tirarlos al suelo, beber agua, etc...), los textos (las instrucciones de Manual de uso, los infinitivos de Angelita, el mapamundi de Cosmopolita, etc.), la música (Fatelo con me, Oh!Sole!, 55921 de Velma, Belmonte, etc.), los ruidos (el camión de la basura de Muriéndose la sirena...) y por último el objeto centralizador: el cuerpo desnudo.

Panoramix es un ejercicio volumétrico y en vivo en el cual las piezas se muestran de forma íntegra. La reubicación de las piezas en el espacio del museo provoca cambios en la naturaleza de las mismas y acentúa su carácter plástico en detrimento de su carácter teatral, sobre todo en las piezas de las dos primeras series, que veían alterado su carácter frontal, la iluminación y una cierta calidad acústica. El orden cronológico se olvidaba y el espectador se situaba al mismo nivel que la artista y los objetos como ya había ocurrido en Still distinguished. Panoramix se estrenó en Live Culture, festival organizado en 2003 en la Tate Modern, que supuso la ocupación definitiva del espacio de las artes visuales por parte del arte de acción, la danza y el teatro, convirtiendo el museo en el lugar transdisciplinar por excelencia. Y al mismo 
tiempo, situó a La Ribot como una de las artistas de referencia de este movimiento y a las Piezas distinguidas como uno de los proyectos artísticos más interesantes en el terreno transdisciplinar y que mejor ha sabido cuestionar los límites conceptuales de la danza y articular un nuevo lenguaje coreográfico a partir del diálogo continuo con otras disciplinas artísticas.

\section{Bibliografía.}

BORDONABA, María: "María Ribot habla sobre la gira de Still distinguished tras el Premio Nacional”, El Cultural, El Mundo, 03/01/2001.

CASTRO FLÓREZ, Fernando: "Still life. Un aproximación (excéntrica) a La Ribot”, La Ribot, Galería Soledad Lorenzo, Madrid, enero 2002.

LA RIBOT: 10 piezas distinguidas y Los trancos del avestruz (Programa de mano), Teatro Pradillo, Madrid, 1994.

- Más distinguidas (Programa de mano), Desviaciones 1997 Sala Cuarta Pared, Madrid, 1997.

- "Still", La Ribot, Galería Soledad Lorenzo, Madrid, 2002.

- "Ese espacio que se abre... donde todo está girando", en Sánchez, J. A. y Conde-Salazar, J. (ed.) Cuerpos sobre blanco, Ediciones de la Universidad de CastillaLa Mancha, Cuenca, 2003a.

- La Ribot, Ed. Merz \& Centre National de la Danse \& Soledad Lorenzo, vol. 1, París, 2004.

LEPECKI, André (2006): Agotar la danza. Performance y política del movimiento, Cuerpo de Letra \# 1, Universidad de Alcalá, Mercat de les Flors, Centro Coreográfico Gallego, 2009.

SÁNCHEZ, José A.: "Cuerpos sobre blanco", en Sánchez, J. A. y CondeSalazar, J. (ed.) Cuerpos sobre blanco, Ediciones de la Universidad de Castilla-La Mancha, Cuenca, 2003.

-"Distinction and Humour ", La Ribot, Ed. Merz \& Centre National de la Danse \& Soledad Lorenzo, vol. 2, París, 2004

-"Nueva danza en Madrid" (b) en Sánchez, J.A. (ed.), Artes de la escena y de la acción en España: 1978-2000, Colección Caleidoscopio, Ediciones de la Universidad de Castilla-La Mancha, Cuenca, 2006.

SANTOS GARCÍA FELGUERA, M.: Las vanguardias históricas (y 2), Colección Historia del Arte, Historia 16, Madrid, 1993. 


\section{DOCUMENTACIÓN AUDIOVISUAL.}

LA RIBOT: treintaycuatropiecesdistinguéesandoneastriptease (c) La Ribot Association Genève en colaboración con La Casa Encendida (Madrid), 2007.

PETER, Luc: La Ribot distinguida (c) Intermezzo Films / SF-DRS/ SRG-SSR idée suisse/ Centre Pompidou, 2004.

$\underline{\text { www.laribot.com }}$

Anexo: Piezas distinguidas.

\section{3 piezas distinguidas}

n. 1 Muriéndose la sirena (Salamanca, 1993). 1'. En memoria de Chinorris

n. 2 Fatelo con me (Salamanca, 1993). 2'. Propietario distinguido: Daikin Air Conditioners (Madrid)

n. 3 Sin título I (Salamanca, 1993). Menos de 1'

n. 4 De la vida violenta (Salamanca, 1993). 2'

n. 5 Eufemia (Madrid, 1993). 2' 45". Música: Fernando López Hermoso

n. 6 ¡Ya me gustaría a mí ser pez! (Salamanca, 1993). 4'. Propietario distinguido: North Wind (Barcelona)

n. 7 Cosmopolita (Madrid, 1994). 40". Propietario distinguido: Nacho Aerssen (Madrid / México)

n. 8 Capricho mío (Madrid, 1994). 2'18". Propietario distinguido: Bernardo Laniado Romero (Nueva York / Madrid)

n. 9 La vaca sueca (Madrid, 1994). 2'30". En memoria de Peter Brown

n. 10 Hacia dónde volver los ojos (Madrid,1994). 1'15". Propietario distinguido: Rafa Sánchez

n. 11 Sin título II (Madrid, 1994). 3'. Propietario distinguido: Olga Mesa

n. 12 La próxima vez (Madrid, 1994). 1'. Propietario distinguido: Juan Domínguez

n. 13 Para ti (Madrid, 1994). 3'

Más Distinguidas (Londres)

n. 14 N. 14 (Madrid, 1996). 3'20". Propietario distinguido: Lois Keidan

n. 15 Numeranda (Madrid, 1996). 2'30". Propietario distinguido: Blanca Calvo (Madrid)

n. 16 Narcisa (Madrid, 1996). 3'20"

n. 17 Sin título IV (Londres, 1997). 2'. Propietario distinguido: Isabelle Rochat (Lausanne)

n. 18 Angelita (Londres, 1997). 1'35". Propietario distinguido: Mal Pelo (Gerona).

n. 1919 equilibrios y un largo (Londres, 1997). 2'30”. Música: Javier López de Guereña. Propietario distinguido: Marga Guergué (Nueva York) 
n. 20 Manual de uso (Londres, 1997). 6'. Propietario distinguido: Thierry Spicher (Lausanne)

n. 21 Poema Infinito (Londres, 1997). 4'. Propietario distinguido: Julia y Pedro Núñez (Madrid)

n. 22 Oh! Compositione! (Londres, 1997). 1'40”. Música: Javier López de Guereña. Propietario distinguido: Robyn Archer (Adelaide, Australia)

n. 23 Sin título III (Londres, 1997). 20". Propietario distinguido: GAG Comunicación (Madrid)

n. 24 Missunderstanding (Londres, 1997). 4'. Música: Rubén González. Propietario distinguido: North Wind (Barcelona)

n. 25 Divana (Londres, 1997). 5'. Vestuario: Pepe Rubio. Propietario distinguido: De Hexe Mathilde Monnier (Montpellier)

n. 26 N. 26 (Londres, 1997). 4'30”. Propietario distinguido: Ion Munduate (San Sebastián)

\section{Still Distinguished}

n. 27 Another Bloody Mary (Londres, 2000). 9'. Propietarios distinguidos: Lois Keidan \& Franko B. (Londres)

n. 28 Outsized Baggage (Londres, 2000). 4'30". Propietario distinguido: Matthieu Doze (París)

n. 29 Chair 2000 (Londres, 2000). 4'30”. Propietario distinguido: Théâtre Arsenic (Lausanne)

n. 30 Candida iluminaris (Londres, 2000). 7'. Propietario distinguido: Victor Ramos (París)

n. 31 De la Mancha (Londres, 2000). 7’. Propietario distinguido: R/B \& Jérôme Bel (París)

n. 32 Zurrutada (Londres, 2000). 7'. Propietario distinguido: Arteleku (San Sebastián)

n. 33 S liquide (Londres, 2000). 7'. Propietario distinguido: Galería Soledad Lorenzo (Madrid)

n. 34 Pa amb tomàquet (Lausanne, 2000). 12'. Propietario distinguido: Gerald Siegmund (Frankfurt) 
